\title{
Distribution of Pucciniastrum symphyti (Pucciniales) in Ukraine
}

\author{
Yuri Ya. TYKHONENKO${ }^{1}$, Oleksandr O. ORLOV ${ }^{2}$ \\ ${ }^{1}$ M.G. Kholodny Institute of Botany, National Academy of Sciences of Ukraine \\ 2 Tereshchenkivska Str., Kyiv 01004, Ukraine \\ yu.ya.tykhonenko@gmail.com \\ ${ }^{2}$ Polisskiy Branch, G.M. Vysotsky Ukrainian Research Institute of Forestry and Forest Melioration (URIFFM) \\ 2 Neskorenykh Str., Dovzhyk village, Zhytomyr Region 10004, Ukraine \\ orlov.botany@gmail.com
}

Tykhonenko Yu.Ya., Orlov O.O. Distribution of Pucciniastrum symphyti (Pucciniales) in Ukraine. Ukr. Bot. J., 2018, 75(5): 441-445.

Abstract. Epiphytotic development of the rust fungus Pucciniastrum symphyti was recorded in May 2016 near Myropil town (Zhytomyr Region, Romaniv District, Ukraine) on Symphytum cordatum. In Ukraine P. symphyti was reported on S. cordatum, $S$. officinale, and only once on $S$. microcalyx. Most records are confined to the west of the country and the dates of collections generally vary from late spring to early summer. We found $P$. symphyti at the easternmost edge of the range of $S$. cordatum. Despite a wide distribution of $S$. officinale throughout the country, $P$. symphyti was not recorded in Ukraine on this species for more than 80 years. Hitherto, the fungus was reported for Europe, the Caucasus and Asia Minor. Due to systemic infection, $P$. symphyti can overwinter in rhizomes of comfrey and therefore does not need aecial host plants for its reproduction. However, the general range of $P$. symphyti does not follow the geographical pattern of the Symphytum species richness, since there are only few its records in the diversity centre of this genus, but mainly reflects the distribution of its aecial host, Abies alba. The article is illustrated by original micrographs.

Keywords: distribution, morphology, rust fungi, Symphytum cordatum

\section{Introduction}

Pucciniastrum symphyti (DC.) McKenzie \& Padamsee in uredinial and telial stages parasitizes several species of the genus Symphytum L., and in aecial stage - of Abies Mill. Previously this fungus was known as Melampsorella symphyti (DC.) Bubák but recent phylogenetic analysis has shown that it should be recombined in the genus Pucciniastrum G.H. Otth (Padamsee, McKenzie, 2014). Pucciniastrum symphyti is one of not so numerous rust species of predominantly European distribution with a few records from the Caucasus and Asia Minor. The genus Symphytum comprises approximately 40 species of the family Boraginaceae originally distributed in Eurasia from the UK, France and Spain in the west to West Siberia, Iran and Israel in the east. The Pontic province is a centre of species diversity and probably a centre of origin of the genus (Hacioğlu, Erik, 2011). In Ukraine ten species of comfrey are recorded (Mosyakin, Fedoronchuk, 1999), but only $S$. officinale L. is widespread throughout the country. In Ukraine $P$. symphyti was observed on $S$. officinale, $S$. cordatum Waldst. \& Kit. ex Willd. and $S$. microcalyx Opiz. All previous records on S. cordatum were confined to the Carpathians.

(C) Yu.Ya. TYKHONENKO, O.O. ORLOV, 2018
The aim of this publication is to report the first records of $P$. symphyti on $S$. cordatum from the lowland part of Ukraine and to provide some data on its occurrence in this country.

\section{Materials and methods}

Systemically infected plants of $S$. cordatum were collected $1.6 \mathrm{~km}$ to the north of Myropil town (Zhytomyr Region, Romaniv District, Ukraine) in a forested floodplain of the small river Fastivka, a right tributary of the river Sluch. The canopy is composed primarily of Alnus glutinosa Mill. and Populus nigra L. The shrub level mainly consists of Swida sanguinea (L.) Opiz and Corylus avellana $\mathrm{L}$. The herbaceous level is dense, with total projective cover of 90-95\%. Symphytum cordatum is the dominant species with projective cover $40-45 \%$. This level also includes Aegopodium podagraria L. (10-15\%), Galium aparine L. (10-15\%), Ficaria verna Huds. (10$15 \%)$, Anemone nemorosa L. (8-10\%), Chaerophyllum aromaticum L. (3-5\%), Lamium maculatum L. (1-3\%), Myosoton aquaticum (L.) Moench (1-3\%), etc. The specimens were studied under a dissecting microscope, labelled and dried for further treatment. Urediniospores mounted in water or lactic acid were investigated by 
light microscopy. Photomicrographs were taken under Primo Star microscope, Canon A300 digital camera and AxioVision 4.7 software, used as well for measurements of microstructures. For scanning electron microscopy, samples were covered with an ultrathin coating of gold by ion beam sputtering unit JFC-1100. Images were obtained by scanning electron microscope JEOL JSM6060 LA.

Analysis of general distribution is based on the data from bibliographic sources and databases available through the Internet, including GBIF Portal (GBIF Secretariat, 2018), USDA Fungal Database (Farr, Rossman, 2018), etc.

The specimens are deposited in Mycological Herbarium of the M.G. Kholodny Institute of Botany, National Academy of Sciences of Ukraine (KW-M).

\section{Results and discussion}

Epiphytotic development of Pucciniastrum symphyti was recorded in May 2016 along a small tributary of the Sluch river. Morphological features of uredinial stage of the collected specimen match their description in the most relevant monographs and handbooks of the rust fungi (Săvulescu, 1953; Wilson, Henderson, 1966; Majewski, 1977). A diagnosis (characteristics of spermogonial, aecial and telial stages are based on literature data), and original illustrations of the species, data on its distribution, morphology and phenology are provided below.

Pucciniastrum symphyti (DC.) McKenzie \& Padamsee, in Padamsee \& McKenzie, Phytotaxa 174(3): 228. 2014. - Uredo symphyti DC., Encycl. Méth. Bot. 8: 232. 1808. - Melampsorella symphyti Bubák, Ber. dt. bot. Ges. 21: 356. 1903. - Melampsora symphyti (DC.) Legg, Vasculum 81(1): 41. 1996. - Thekopsora symphyti (DC.) J. Müll., Czech Mycol. 62(1): 97. 2010.

Spermogonia on the lower, rarely on the upper side of needles, subcuticular, orange. Aecia on the lower side of needles in two rows; peridium whitish, shortcylindrical, often slightly flattened laterally, up to $0.7 \mathrm{~mm}$ long, delicate, opening at the apex, rapidly destroyed. Aeciospores globose, broadly ellipsoidal, ovoid, often slightly irregular, $25-40 \times 20-30 \mu \mathrm{m}$; cell wall is thin, colorless, densely covered with small cylindrical warts $1.5-2.5 \mu \mathrm{m}$ height. Uredinia on the lower side of the leaves, more or less densely cover the entire surface of the leaf (Fig. 1,a), rounded, up to $0.4 \mathrm{~mm}$ in diameter, initially vesicular, covered with epidermis and peridium, after their destruction, pulverulent, yellow-orange (Fig. 1, b, c); urediniospores globose, ovate, pyriform, ellipsoidal or irregularly elongate, $22-36 \times 18-26 \mu \mathrm{m}$; cell wall is about $1 \mu \mathrm{m}$ thick, with spacing $2-3 \mu \mathrm{m}$ covered with small spines (Fig. 1, $d, e, f$ ). Telia cover significant part of the lower surface of leaves, white or pink. Teliospores inside epidermal cells, mostly numerous and densely packed, $11-18 \times 9-15 \mu \mathrm{m}$; cell wall colorless or slightly yellowish, slightly thickened, smooth.

\section{Distribution in Ukraine (see also Fig. 2)}

On Symphytum cordatum Waldst. \& Kit. ex Willd.: Ivano-Frankivsk Region, Tlumach, 48 $51^{\prime} \mathrm{N}, 24^{\circ} 59^{\prime} \mathrm{E}$, 04.1914 (Wróblewski, 1916); Maniava, 48³9' N, $24^{\circ} 21^{\prime}$ E, 17.05.1988, leg. Yu.Ya. Tykhonenko (KW-M 70945); Kniazhdvir, 48 34' N, 245' E, 05.1912 (Wróblewski, 1913, 1916); Molodiatyn, 4831' N, 2450' E, 05.1914 (Wróblewski, 1916); Pistyn, 48 $20^{\prime} \mathrm{N}, 2^{\circ} 03^{\prime}$ E, 16.05.1988, leg. Yu.Ya. Tykhonenko (KW-M 70946); Lanchyn, 48³2' N, 244' E, 05.1914 (Wróblewski, 1916); Chornohora, Pozhyzhevska mountain, $48^{\circ} 08^{\prime} \mathrm{N}, 24^{\circ} 31^{\prime}$ E, 0608.1910 (Chmielewski, 1910). Lviv Region, Pidhirtsi, $49^{\circ} 15^{\prime} \mathrm{N}, 23^{\circ} 55^{\prime}$ E, 22.05 .1917 (Petrak, 1925). Ternopil Region, Buchach, $49^{\circ} 03^{\prime} \mathrm{N}, 25^{\circ} 22^{\prime}$ E (Namysłowski, 1911). Zakarpatska Region, Shyrokyi Luh, $48^{\circ} 12^{\prime} \mathrm{N}$, $23^{\circ} 45^{\prime}$ E, 16.06.1954, leg. M.F. Smitska (KW-M 22642). Zhytomyr Region, Myropil, 50 $08^{\prime} 33^{\prime \prime} \mathrm{N}, 27^{\circ}$ 41' 23" E, 03.05.2016, leg. O.O. Orlov (KW-M 70947). On $S$. microcalyx Opiz: Ternopil Region, Zalishchyky, $48^{\circ} 39^{\prime}$ N, $25^{\circ} 44^{\prime}$ E (Rouppert, 1911). On S. officinale L.: Chernihiv Region, Irzhavets, $50^{\circ} 52^{\prime} \mathrm{N}, 32^{\circ} 33^{\prime} \mathrm{E}$, 05.08.1916 (Bondartseva-Monteverde, 1921); Pryluky, $50^{\circ} 35^{\prime} \mathrm{N}, 32^{\circ} 23^{\prime} \mathrm{E}$ (Transhel, 1939). Ivano-Frankivsk Region, Chernelytsia, $48^{\circ} 48^{\prime} \mathrm{N}, 25^{\circ} 25^{\prime} \mathrm{E}, 16.07 .1913$ (Wróblewski, 1914). Kharkiv Region, Kharkiv, 5000' N, $36^{\circ} 13^{\prime}$ E, (Transhel, 1939). Khmelnytskyi Region, Kamianets-Podilskyi, 4840' N, 2634' E, 15.05.1927, leg. Panasiuk. Kyiv Region, Bila Tserkva, 49 $47^{\prime} \mathrm{N}$, 3007' E (Transhel, 1939), 22.05.1928 (Hrodzinska, 1929). Lviv Region, Obroshyne, $49^{\circ} 47^{\prime}$ N, 2352' E, 07.07.1917 (Wróblewski, 1922). Ternopil Region,



General distribution. Europe: Austria, Belgium, Bulgaria, Czech Republic, Denmark, Estonia, Finland, France, Germany, Greece, Hungary, Italy, Lithuania, Netherlands, Norway, Poland, Romania, Russia, Slovakia, Slovenia, Sweden, Switzerland, Ukraine, United Kingdom; Asia: Armenia, Georgia, Turkey.

Due to systemic infection, $P$. symphyti can overwinter in rhizomes of comfrey and therefore does 


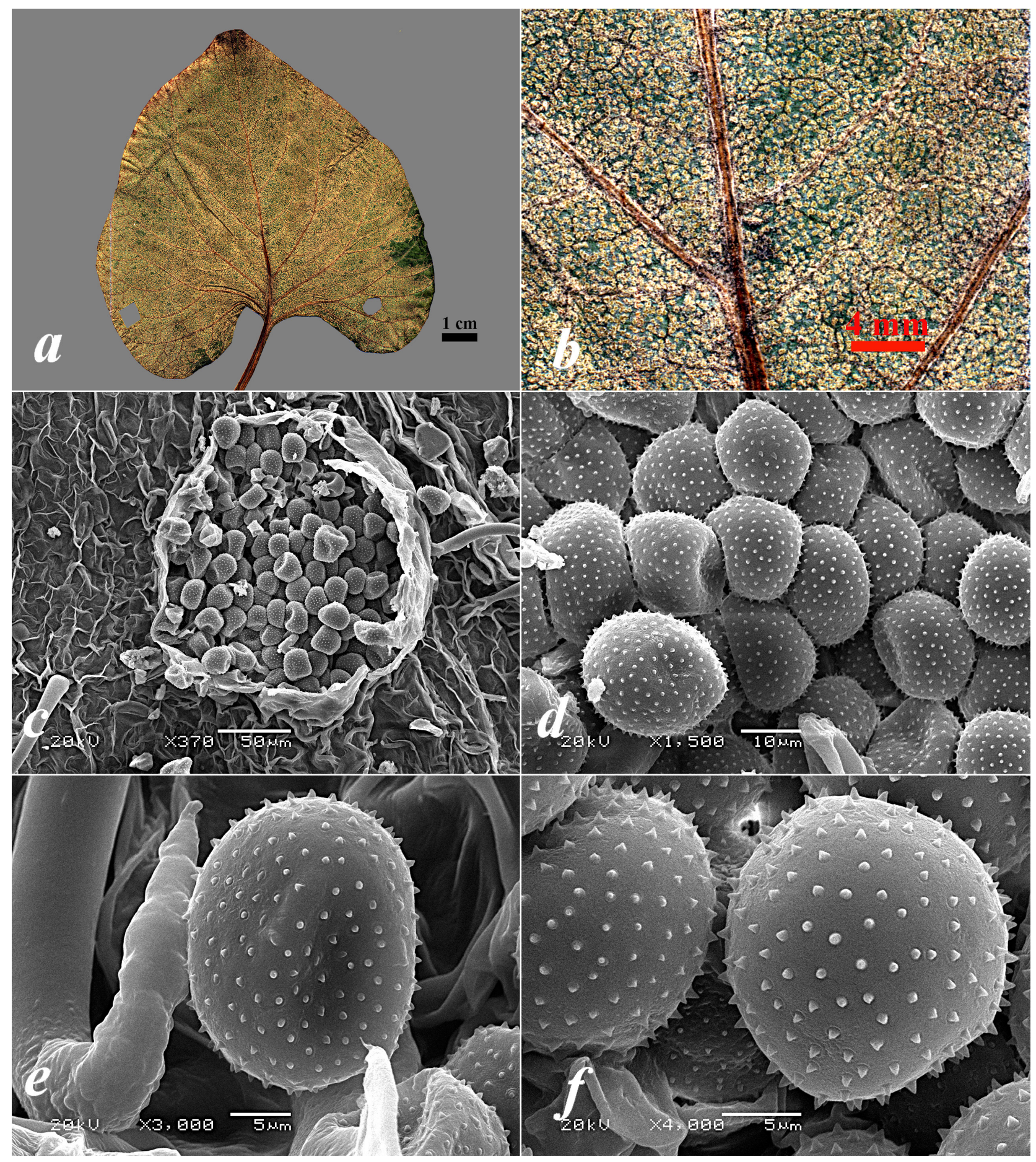

Fig. 1. Pucciniastrum symphyti: $a$ - habit of uredinia on Symphytum cordatum (scale bar $=1 \mathrm{~cm}$ ); $b$ - fragment of comfrey leaf showing erumpent uredinia (scale bar $=4 \mathrm{~mm}$ );c- scanning electron microscopy of uredinium (scale bar $=50 \mu \mathrm{m}) ; d-$ scanning electron microscopy of urediniospores inside uredinium (scale bar $=10 \mu \mathrm{m}$ ); $e, f$ - scanning electron microscopy of scattered urediniospores (scale bars $=5 \mu \mathrm{m}$ ) 


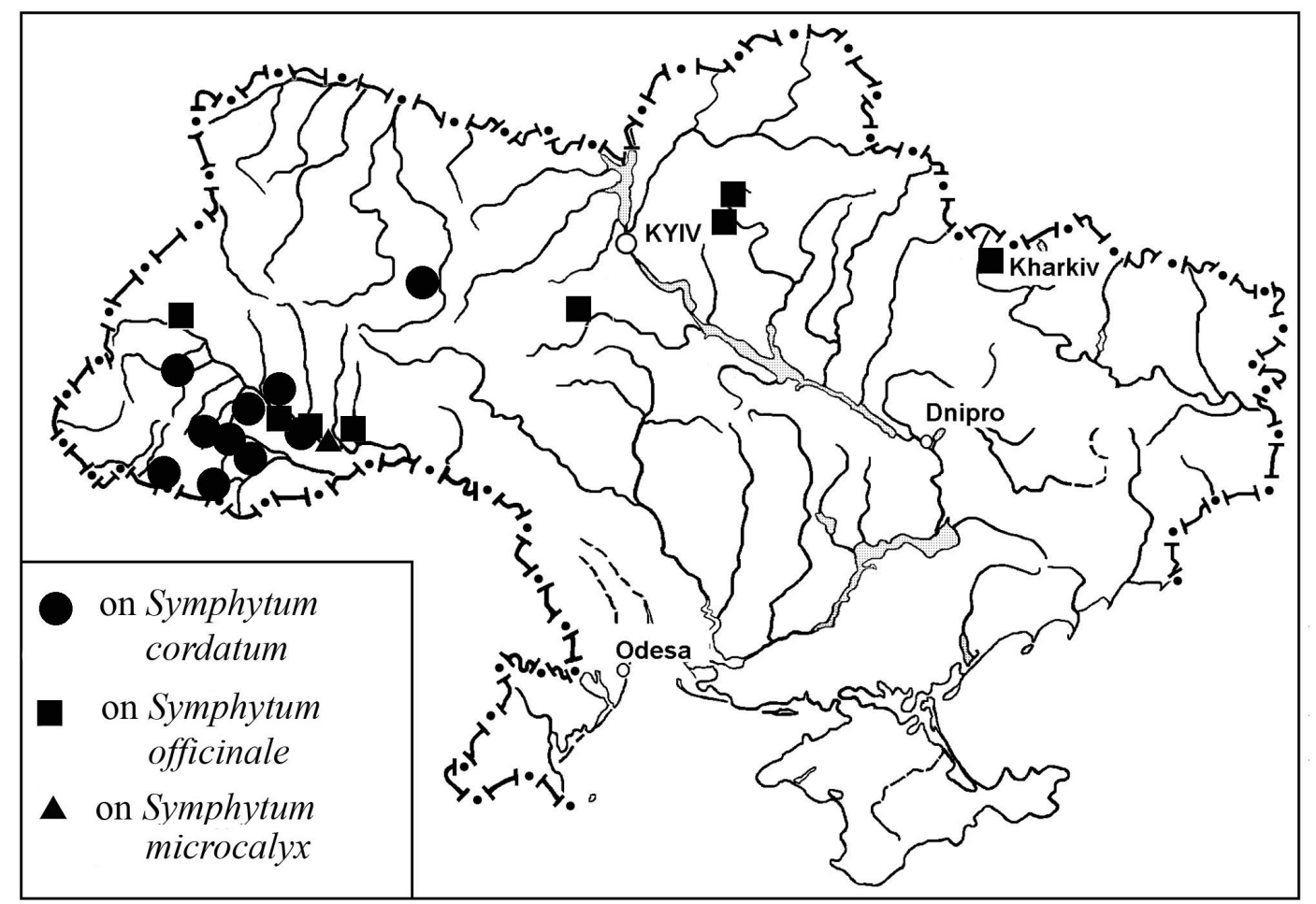

Fig. 2. Distribution of Pucciniastrum symphyti in Ukraine

not need aecial host plants for its reproduction (Wilson, Henderson, 1966). However, the general range of $P$. symphyti does not follow geographical pattern of the Symphytum species richness since there are only few its records in the diversity centre of this genus, but mainly reflects the distribution of its aecial host Abies alba Mill.

In Ukraine P. symphyti was observed on $S$. cordatum, $S$. officinale and only once on $S$. microcalyx. Most records are confined to the west of the country and the dates of collections generally vary from late spring to early summer. Symphytum cordatum is distributed mostly in the Carpathians and surrounding areas (the Czech Republic, Hungary, Poland, Romania, Slovakia, and Ukraine). In Ukraine there are some isolated populations of this species at a considerable distance from the Carpathians (Khmelnytsky, Ternopil, Zhytomyr regions) (Kobiv, 2007). We found P. symphyti at the easternmost edge of the range of $S$. cordatum. Despite wide distribution of $S$. officinale throughout the country, $P$. symphyti was not recorded in Ukraine on this species for more than last 80 years.

\section{Acknowledgements}

We are grateful to N.S. Novichenko, a staff member of the M.G. Kholodny Institute of Botany NASU, for his technical assistance with scanning electron microscopy.

\section{REFERENCES}

Bondartseva-Monteverde V.N. Materialy po mikologicheskomu obsledovaniyu Rossii, 1921, 5(4): 1-32. [Бондарцева-Монтеверде В.Н. К микологической флоре Полтавской губернии. Грибы, собранные С.С. Ганешиным в 1916-1917 гг. и обработанные В.Н. Бондарцевой-Монтеверде. Материалы по микологическому обследованию России, 1921, 5(4): 1-32].

Chmielewski Z. Zapiski grzyboznawcze z Czarnej Hory. Kosmos, 1910, 35(7/9): 804-813.

Farr D.F., Rossman A.Y. Fungal Databases, U.S. National Fungus Collections, ARS, USDA. Retrieved August 29, 2018. Available at: https://nt.ars-grin.gov/ fungaldatabases/

GBIF Secretariat: GBIF Backbone Taxonomy. Available at: https://doi.org/10.15468/39omei Accessed via https:// www.gbif.org/species/3380345 on 2018-08-29.

Hacioğlu B.T., Erik S. Phylogeny of Symphytum L. (Boraginaceae) with special emphasis on Turkish species. African J. Biotechnol., 2011, 10: 15483-15493.

Hrodzinska V.P. Zapysky Bilotserkivskoho silskohospodarskoho politekhnikumu, 1929, 1(1): 193-200. [Гродзінська В.П. Матеріяли до грибної флори Білоцерківщини (із робіт катедри сільськогосподарської ботаніки), Записки Білоцерків. с.-г. політехнікуму, 1929, 1(1): 193-200].

Kobiv V.M. Naukovi zapysky Derzhavnoho pryrodoznavchoho тиzеуи, 2007, 23: 137-144. [Кобів В.М. Поширення та індивідуально-групові параметри Symphytum cordatum Waldst. \& Kit. ex Willd. в умовах рівнини заходу 
України. Наук. записки держ. природознавч. музею, 2007, 23: 137-144].

Majewski T. Podstawczaki (Basidiomycetes), Rdzawnikowe (Uredinales). Flora Polska. Rośliny zarodnikowe Polski $i$ ziem ościennych. 9. Grzyby (Mycota). Warszawa; Kraków: Państw. Wydaw. Naukowe, 1977, 396 pp.

Mosyakin S.L., Fedoronchuk M.M. Vascular plants of Ukraine: A nomenclatural checklist. Kiev, 1999, xxiii + $345 \mathrm{pp}$.

Namysłowski B. Prodromus Uredinearum Galiciae et Bukowinae. Sprawozdanie Komisji Fizjograficzney Polsk. Akad. Umiejętności, 1911, 45(3): 65-146.

Padamsee M., McKenzie E.H.C. A new species of rust fungus on the New Zealand endemic plant, Myosotidium, from the isolated Chatham Islands. Phytotaxa, 2014, 174(3): 223-230. Available at: http://doi.org/10.11646/ phytotaxa.174.4.3

Petrak F. Beiträge zur Pilzflora Südost-Galiziens und der Zentralkarpathen. Hedwigia, 1925, 65(6): 179-330.

Rouppert K. Przyczynek do znajomości grzybów Galicji i Bukowiny. Kosmos, 1911, 36: 936-944.

Săvulescu T. Monografia uredinalelor din Republica Popularâ Românâ. Bucureşti: Editura Academiei RPR, 1953, vol. 2, $727 \mathrm{pp}$.

Transhel [Tranzschel] V.G. Obzor rzhavchinnykh gribov SSSR. Moscow: Izd-vo AN SSSR, 1939, 426 pp. [Траншель В.Г. Обзор ржавчинных грибов СССР. М.: Изд-во AH CCCP, 1939, 426 c.].

Wilson M., Henderson D.M. British rust fungi. London: Cambridge Univ. Press, 1966, 384 pp.

Wróblewski A. Przyczynek do znajomości grzybów Pokucia. I. Sprawozdanie Komisji Fizjograficzney Polsk. Akad. Umiejętności, 1913, 47(2): 147-178.

Wróblewski A. Przyczynek do znajomości grzybów Podola. I. Sprawozdanie Komisji Fizjograficzney Polsk. Akad. Umiejętności, 1914, 48(2): 3-15.

Wróblewski A. Drugi przyczynek do znajomości grzybów Pokucia i Karpat Pokuckich. Sprawozdanie Komisji Fizjograficzney Polsk. Akad. Umiejętności, 1916, 50: 82-154.

Wróblewski A. Wykaz grzybów zebranych w latach 19131918 z Tatr, Pienin, Beskidów Wschodnich, Podkarpacia, Podola, Roztocza i innych miejscowości. I. Sprawozdanie Komisji Fizjograficzney Polsk. Akad. Umiejętności, 1922, 55-56: $1-50$.

Recommended for publication by

Submitted 25.09.2018

V.P. Heluta

Тихоненко Ю.Я. ${ }^{1}$, Орлов О.О. ${ }^{2}$ Поширення Pucciniastrum symphyti (Pucciniales) в Україні. Укр. бот. журн., 2018, 75(5): 441-445.

${ }^{1}$ Інститут ботаніки ім. М.Г. Холодного НАН України вул. Терещенківська, 2, Київ 01004, Україна

${ }^{2}$ Поліський філіал Українського науково-дослідного інституту лісового господарства та агролісомеліорації (УкрНДІЛГА) ім. Г.М. Висоцького

вул. Нескорених, 2, с. Довжик 10004,

Житомирський р-н, Житомирська обл., Україна
У травні 2016 р. біля смт Миропіль (Житомирська обл., Україна) на Symphytum cordatum було відмічено епіфітотійний розвиток іржастого гриба Pucciniastrum symphyti. В Україні $P$. symphyti відмічався на $S$. cordatum, $S$. officinale і одноразово на $S$. microcalyx. Більшість зразків було зібрано на заході країни і дати збору в основному відносяться до періоду від пізньої весни до раннього літа. Наша знахідка $P$. symphyti розташована на східній межі ареалу $S$. cordatum. Незважаючи на широке розповсюдження $S$. officinale по всій країні, $P$. symphyti на цьому виді в Україні не реєструвався протягом понад 80 останніх років. Цей вид гриба поширений в Європі, на Кавказі та в Малій Азії. Завдяки системному характеру ураження $P$. symphyti здатний перезимовувати в кореневищах живокосту, і тому не потребує еціального господаря для свого відновлення. Проте характер загального поширення P. symphyti не пов'язаний із регіонами найвищого видового різноманіття роду Symphytum (у центрі різноманітності відмічено лише кілька знахідок), а в основному відображує поширення його еціального живителя Abies $a l b a$. Стаття ілюстрована оригінальними мікрофотографіями.

Ключові слова: поширення, морфологія, іржасті гриби, Symphytum cordatum

Тихоненко Ю.Я. ${ }^{1}$, Орлов А.А. ${ }^{2}$ Распространение

Pucciniastrum symphyti (Pucciniales) в Украине.

Укр. бот. журн., 2018, 75(5): 441-445.

${ }^{1}$ Институт ботаники им. Н.Г. Холодного НАН Украины ул. Терещенковская, 2, Киев 01004, Украина

${ }^{2}$ Полесский филиал Научно-исследовательского института лесного хозяйства и агролесомелиорации (УкрНИИЛХА) им. Г.Н. Высоцкого

ул. Нескореных, 2, с. Довжик 10004, Житомирский р-н, Житомирская обл., Украина

В мае 2016 г. вблизи пгт Мирополь (Житомирская обл., Украина) на Symphytum cordatum было отмечено эпифитотийное развитие ржавчинного гриба Pucciniastrum symphyti. В Украине P. symphyti отмечался на $S$. cordatum, S. officinale и однажды на S. microcalyx. Большинство образцов было собрано на западе страны и даты сбора в основном относятся к периоду от поздней весны до раннего лета. Наша находка P. symphyti находится на восточной границе ареала $S$. cordatum. Несмотря на широкое распространение $S$. officinale по всей стране, $P$. symphyti на этом виде в Украине не регистрировался на протяжении более чем 80 последних лет. Этот вид гриба распространен в Европе, на Кавказе и в Малой Азии. Благодаря системному характеру поражения вид $P$. symphyti способен перезимовывать в корневищах окопника, и поэтому не нуждается в эциальном хозяине для своего возобновления. Однако, характер обшего распространения P. symphyti не связан с регионами наивысшего видового разнообразия рода Symphytum (в центре разнообразия отмечено лишь несколько находок), а в основном отражает распространение его эциального питающего растения Abies alba. Статья иллюстрирована оригинальными микрофотографиями.

Ключевые слова: распространение, морфология, ржавчинные грибы, Symphytum cordatum 